\title{
Information technology and innovative drainage management practices for selenium load reduction from irrigated agriculture to provide stakeholder assurances and meet contaminant mass loading policy objectives
}

\author{
Nigel W.T. Quinn PhD, P.E., D.WRE. Group Leader \\ HydroEcological Engineering Advanced Decision Support \\ Berkeley National Laboratory \\ 1 Cyclotron Road, Bld. 70A-3317H \\ Berkeley, CA 94720 \\ Telephone : 5104867056 Fax : 5104867152 \\ E-mail : nwquinn@lbl.gov
}

\begin{abstract}
Many perceive the implementation of environmental regulatory policy, especially concerning non-point source pollution from irrigated agriculture, as being less efficient in the United States than in many other countries. This is partly a result of the stakeholder involvement process but is also a reflection of the inability to make effective use of Environmental Decision Support Systems (EDSS) to facilitate technical information exchange with stakeholders and to provide a forum for innovative ideas for controlling non-point source pollutant loading. This paper describes one of the success stories where a standardized Environmental Protection Agency (EPA) methodology was modified to better suit regulation of a trace element in agricultural subsurface drainage and information technology was developed to help guide stakeholders, provide assurances to the public and encourage innovation while improving compliance with State water quality objectives. The geographic focus of the paper is the western San Joaquin Valley where, in 1985, evapoconcentration of selenium in agricultural subsurface drainage water, diverted into large ponds within a federal wildlife refuge, caused teratogenecity in waterfowl embryos and in other sensitive wildlife species. The fallout from this environmental disaster was a concerted attempt by State and Federal water agencies to regulate non-point source loads of the trace element selenium. The complexity of selenium hydrogeochemistry, the difficulty and expense of selenium concentration monitoring and political discord between agricultural and environmental interests created challenges to the regulation process. Innovative policy and institutional constructs, supported by environmental monitoring and the web-based data management and dissemination systems, provided essential decision support, created opportunities for adaptive management and ultimately contributed to project success. The paper provides a retrospective on the contentious planning process and offers suggestions as to how the technical and institutional issues could have been resolved faster through early adoption of some of the core principles of sound EDSS design.
\end{abstract}

Keywords: Selenium drainage, TMDL, decision support, water quality 


\section{Introduction}

Actions to control and regulate environmental pollutants often take different paths from the stage of initial problem recognition, through solution identification and policy implementation in Europe and in the United States. Jasanoff (2005) and Brickman (1985) et al. have suggested, based on comparative studies of pollutant regulation in the United Kingdom and the United States, that although the paths to regulation may differ - the end final outcomes are often similar and surprisingly provide quite consistent levels of pollution protection. The researchers suggest that in Europe, where government agencies are generally held in higher regard and more trusted, the path to regulation of a chemical pollutant in the environment is a relatively linear process albeit, sometimes a long, drawn-out one where the machinery of government works through commissions, committees and other government sanctioned entities to find cost effective and socially acceptable ways of achieving pollutant reduction goals. In the United States and other newer democracies, where society is encouraged to have a more critical view of government and its function - environmental pollutant regulation policy can take a more tortuous path between the first attempts at regulating a pollutant and the point in time where environmental targets are achieved. The result is more of a roller-coaster ride involving litigation, the media, adversarial encounters between stakeholders concerned with outcomes and impacts, false starts and often large financial expenditures to see the process from start to finish.

\section{Pollutant regulation}

Environmental pollution regulation in California is complex. Federal environmental regulations constitute a de-minimus set of policy directives that each state interprets according to its own State office of environmental protection. Non-point source pollution is regulated by Total Maximum Daily Loads (TMDL's), which are pollutant load limits determined for a contributing watershed that attempts to maximize attainment of numerical water quality objectives for receiving waters of the state using low flow hydrologic conditions, appropriate factors of safety and non-attainment excursion rates. The TMDL is a convenient regulatory tool that encourages the trading of pollutant credits - where the ability to pollute has an economic value and can be traded amongst dischargers to receiving waters of the State. Failure to meet State water quality standards or numerical water quality objectives is typically penalized through the imposition of a fine that is typically assessed in proportion to the magnitude of the exceedence. In this system the market place is expected to determine the equilibrium point where the demand for and supply of pollutant credits are equated.

The success of the TMDL concept as a regulatory tool is testimony to the consistency of the methodology and its ability to provide quantitative measures of application outcome. The TMDL concept breaks down in regions such as the western States where hydrology is often extreme, with wet hydrologic years capable of causing severe flooding interspersed with periods of drought which cause severe stress on the water delivery system. The TMDL concept also is 
imperfect as a regulatory tool when dealing with pollutants with a complex geochemistry such as selenium, which exist in various toxic valence states within the environment - with aqueous mobility that is severely retarded when the metalloid is present in its reduced state. Selenium is a unique naturally occurring element that is essential to human nutrition at very low levels but can cause harm to fish and avian life once it bio-concentrates above certain thresholds in the environment. At high concentrations it is toxic to humans. Analytical methods do not exist to obtain accurate selenium concentration levels in the environment except using laboratory procedures - making the pollutant difficult to regulate using traditional TMDL methodologies.

Selenium is present in the alluvial sediments that comprise the Coast Range mountains that bound the west-side of the San Joaquin Basin. Ephemeral flood flows have eroded these sediments and broadcast them over the floodplain in the form of an alluvial fan. Rainfall and irrigation have leached these soils of selenium over millennia in the case of rainfall and over the past 120 years in the case of irrigation applications. Selenium has evapo-concentrated in shallow groundwater in poorly drained areas reaching levels in the thousands of parts per billion in some low-lying areas. When subsurface tile drainage was introduced irrigation recharge displaced a portion of this selenium enriched groundwater into these tile drains. The relationship between irrigation applications and selenium loads in subsurface tile drainage is complex given the spatial heterogeneity of the soils and their parent materials, the differences in their infiltration rates and the fact that evapo-concentration of salts and selenium in shallow groundwater decreases with depth to groundwater. Approximately 400,000 hectares on the west-side of the San Joaquin Basin are underlain by groundwater with elevated selenium concentrations.

\section{Selenium teratogenecity at Kesterson Reservoir}

Environmental regulation of irrigated agriculture in California began in earnest as a result of the discovery of selenium teratogenecity in waterfowl embryos at Kesterson Reservoir in 1984. Subsurface agricultural drainage water from approximately 3,500 hectares of irrigated farmland within the 300,000 hectare Westlands Water District (WWD) was diverted into Kesterson Reservoir, a federally constructed terminal drainage facility that became managed by the US Fish and Wildlife Service. The Drain that connected WWD to Kesterson Reservoir was designed to provide drainage service to the District and other salt affected areas on the west-side of the San Joaquin Valley. WWD is the largest irrigation water district in the United States and the largest contributor to the economy of the San Joaquin Valley. Evapoconcentration of selenium within the 550 hectares of ponds that were managed to attract waterfowl caused ambient pond selenium levels to exceed levels subsequently discovered to lead to gross deformities in waterfowl embryos. General reaction to this event was a public relations disaster for irrigated agriculture and led to a moratorium on discharges of selenium tainted water to the State's receiving waters and the plugging of all tile drains in the selenium affected area of WWD. 
As policy makers struggled to develop appropriate regulatory approaches for dealing with the selenium problem it became clear that traditional pollutant control practices would not be effective. First, selenium is a trace element, not a nutrient or a traditional pollutant that is introduced to the groundwater system through human activity. Second, selenium is very difficult and expensive to monitor. There are no existing sensor technologies that can be field deployed to measure selenium concentrations. In the case of Kesterson Reservoir - despite convincing scientific data that supported a "wet-flex" method for immobilizing soluble selenium - the entire site was backfilled with clean fill-dirt to bury the selenium-rich pond sediments and minimize the risk of having selenium diffuse upwards into the surface ponded water. At about the same time, a proposal was made to the US Bureau of Reclamation to use the San Luis Drain (the conveyance that had previously been used to deliver WWD subsurface drainage water to Kesterson Reservoir) to collect all selenium tainted agricultural drainage generated within a 45,000 hectare region to the north of the WWD. The most significant benefit of this proposal, subsequently named the Grassland Bypass Project, was it that it removed selenium drainage from more than $160 \mathrm{~km}$ of wetland delivery channels which carried agricultural drainage as part of a "flip-flop" dual-use conveyance arrangement between the wetland entities and the agricultural water districts. In addition to removing the risk of selenium contamination in surface water deliveries to wetlands - the Grasslands Bypass Project (GBP) has helped to improve the reliability of water deliveries to wetlands and drainage service to agricultural water districts while providing greater protection to the San Francisco Bay-Delta ecosystem, the source of drinking water for two-thirds of California's population of thirty five million. The GBP has been among the most successful voluntary non-point source pollutant regulation projects of the past two decades - demonstrating the advantages of an adaptive approach to TMDL implementation that retains stakeholder operational flexibility and encourages grower innovation.

(http://www.usbr.gov/mp/grassland/)

\section{Grasslands Bypass Project}

Use of the federally-owned San Luis Drain conveyance as a bypass for selenium drainage (Grasslands Bypass) was made contingent on the signing of a "Use Agreement”. This "Use Agreement” took more than six years of consensus-seeking meetings and group discussions to finalize and, although the final document was signed by four federal and two state agencies, the Technical Advisory Committee that oversaw the project had swollen in size to almost 100 people with active participation by local government and privately funded environmental organizations. An innovative alternative to the traditional TMDL approach to pollutant regulation was developed during the negotiation process (Quinn and Hanna, 2003) that addressed the cost and difficulty of monitoring selenium and the inter-annual and seasonal variation of Basin hydrology (Quinn, 1996; Quinn and Karkoski, 1998; Quinn et al. 1998; Quinn et al. 2006). A Total Monthly Maximum Load model was developed (Karkoski, 1994) which classified historic San Joaquin Basin hydrology into three water years types (critical, dry/below normal and above 
normal/wet) and into four seasonal groups (Sept-Nov, Dec-Jan, Feb-May, Jun-Aug). A monthly equivalent flow to the standard 4-day average flow in the standard TMDL methodology was calculated to address the fact that most agricultural water districts have neither sufficient manpower or financial resources to measure selenium loads on daily basis. Changing the averaging period from a 4-day average to a monthly average increased the allowable load by between 24 and 32 \% (Karkoski, 1994). Relaxation of the allowable exceedance rate from once in three years to once every 5 months increased the annual allowable load by between $60 \%$ and $120 \%$. Karkoski (1994) found that the waste load allocation was more sensitive to the acceptable rate of violation than the averaging period of the selenium objective. The monthly mean selenium concentration objective of $5 \mathrm{ug} / \mathrm{L}$ was used to determine SJR assimilative capacity. Karkoski checked his methodology by comparing historic selenium loads for the period 19861992 with calculated allowable selenium loads and making sure the rates of violation were equivalent. Adoption of the TMML allowed the development of selenium load targets for the project period (allowable selenium loads were reduced by $5 \%$ per year in years three, four and five of the project with a long term goal of full compliance with the $5 \mathrm{ug} / \mathrm{L}$ selenium load objective) and provided a metric with which to evaluate the success of the project.

Too often in the process of environmental regulation a "one size fits all” approach is taken with tools such as the TMDL - where strict adherence to the standard TMDL methodology leads to an over-constrained system or a set of load objectives that are unrealistic or very costly to administer. The GBP example illustrated that better policy instruments can be crafted by taking an adaptive approach and by developing these strategies ahead of the final rounds of negotiation. The TMML was published in June, 1994 - the Use Agreement negotiation process lasted from October 1991 to September $26^{\text {th }} 1996$, when the GBP was officially sanctioned.

In 1991, when negotiations with respect to implementation of the TMML first started, the internet was still in its infancy and the dissemination of data and information via the world wide web was just getting started through public access to primitive scripting languages. The power of these tools gradually was revealed as the project moved from concept into implementation and the challenges of managing a compliance monitoring plan and helping to meet expectations of a polarized multi-interest stakeholder group became paramount. Many mistakes were made along the way and many opportunities squandered as stakeholder representatives jockeyed for political advantage and environmental assurances - sometimes to the detriment of ultimate project goals.

The remainder of this paper attempts to distill some of the lessons learned during the long drawnout negotiation period and since GBP implementation. The term "Environmental Decision Support System" (EDSS) was not in common parlance when the GBP was first implemented now in hindsight the successes and failures of the environmental information management system that was developed for the project can be judged against the more formalized principles of sound EDSS design. 


\section{Environmental monitoring and decision support for stakeholder assurances}

The major challenge to project implementation, that became apparent from the very beginning, was one of providing stakeholder assurances. The process of negotiating the project scope and the details of the "Use Agreement" for the San Luis Drain followed no roadmap since no project of this sort had been previously attempted by the project proponents - especially one involving as many independent parties. Fundamental to providing environmental assurances was the formulation of a comprehensive environmental compliance monitoring plan. The compliance monitoring plan had as its' primary goals the achievement of strict monthly and annual selenium load targets, based on continuous monitoring that were set based on historical loading patterns, and an initial 5-year schedule of incremental selenium load reductions (Swain and Quinn, 1991; Environmental Defense Fund, 1994), with a long-term goal of the attainment of strict receiving water concentration objectives of $5 \mathrm{ppb}$ (Figure 1). Annual load targets were set at 3,300 kg per year, less than the sum of the monthly load targets. The annual selenium load targets were to be reduced by $5 \%$ per year during the last 3 years of the 5 year project, to meet TMML load limits after that with long-term compliance with the $5 \mathrm{ug} / \mathrm{L}$ selenium concentration objective for discharges into receiving waters. Incremental drainage incentive fees of up to $\$ 250,000$ were to be levied for exceedence of either annual or mean monthly selenium load targets above $20 \%$ - it was critical that the selenium targets be economically attainable and that the incentive fees not be overly punitive (Wichelns and Nelson, 1989; Wichelns and Weinberg, 1990). The first major obstacle to implementation of the project, after the "Use Agreement" had been formalized, was to adopt and finance the compliance monitoring plan - which provided assurances that the terms of the "Use Agreement" were being honored and that the benefits promised by the project would be realized.

Critical lessons learned during this final phase of GBP implementation are discussed below. These are presented in the form of general principles that it is hoped may help guide future environmental monitoring efforts and EDSS design on similar projects.

\subsection{Develop monitoring plans that include all possible constituents and at sites and pare according to constraints of budget and personnel}

Monitoring is central to EDSS design and yet is often overlooked. Every project is unique and environmental monitoring should be customized to provide assurances to project stakeholders that goals are being met within the constraints of available manpower and budget. A fundamental error that was made early in the GBP was to attempt to develop a monitoring program by stakeholder consensus without proper guidelines, clear-cut scientific objectives or clear budgetary constraints. As a consequence the monitoring plan was over four years in development. Initial versions of the plan included every conceivable environmental chemical of concern and because there was no initial agreement on budget limits or who should pay - the early cost estimates were in excess of $\$ 500,000$ per year. When representatives from participating State and Federal agencies, who served on the Technical Advisory Committee (TAC), which provided project oversight, were reassigned - monitoring plan negotiations 
oftentimes started anew. A more efficient approach would have been to develop a project website or information dissemination system early-on and use this as a way of providing access to meeting minutes and a record of important consensus decisions reached at every meeting. In a many-stakeholder environment, such as existed in this project, individuals sometimes lost sight of project goals. For example - beginning with a comprehensive compliance monitoring plan that includes every conceivable constituent and monitoring location and then paring down this monitoring plan in a reasoned manner (with documentation of decisions reached), as constraints of budget, personnel and science are factored into the decision process, could have provided a clear record of the path taken and aided convergence to stakeholder consensus. A project website could have provided access to stakeholder group that might have been under-represented - minimizing the risk of public dissent during the occasional public information meetings.

\subsection{Perform due diligence in identifying all possible stakeholder interests and identify legitimate representatives for these interests at the beginning of the project to avoid disruptive politically-motivated discord}

Projects that rely on stakeholder consensus may be more vulnerable to political intrigue where less powerful special interests can exert disproportional influence unless countered by clear and transparent decision making strategies and an early commitment to inclusivity. In the GBP, membership of the TAC, that provided project oversight, was amorphous and not clearly defined at the beginning of the project. As a consequence individuals with a political agenda (often at odds with the more objective stance of their employer) were given legitimacy equal to agency representatives - those whose agencies were co-signatories of the "Use Agreement". This proved an impediment to progress. Having a more structured and formal policy for decision making where agencies roles were defined early on and better use of information technology for recording critical decisions would have likely resulted in faster progress. A project website was eventually created and routine monthly e-mailing of compliance monitoring data summaries to the stakeholder group http://www.sfei.org/grassland/reports/gbppdfs.htm began in the second year of the project (Figure 2). The website provides complete data summaries of the hydrologic, water chemistry, biological and toxicity data collected by the various agencies involved in the project. The website also provides a link to the California Regional Water Quality Control Board which publishes monthly water quality data at eleven watershed monitoring sites and daily data at the compliance monitoring site (Site B). In Figure 2 the monthly selenium loads for October and November 2007 (most current data at the time) appear in the right-most column these can be compared to the allowable selenium loads in the middle column for all 12 months. As previously discussed the monthly allowable selenium loads have been reduced each year, under the terms of the "Use Agreement" - in Figure 2 the allowable selenium load for October has been reduced from $328 \mathrm{lbs}(150 \mathrm{~kg}$ ) for the 2005/2006 water year to $260 \mathrm{lbs}(118 \mathrm{~kg})$ for the 2006/2007 water year. 
One particular astute decision was to employ a highly-regarded private environmental organization (San Francisco Estuary Institute- SFEI ), which specializes in environmental compliance monitoring, to manage the project database and publish monthly project data reports on their public website. This created an insulating layer between project proponents and the environmental community and diluted political influence on project outcome. This was especially fortuitous in the first and second years of the project, where el-Nino conditions caused severe watershed flooding and selenium loads in excess of target limits - and could have given the impression that the project was not living up to its claimed benefits. Accurate and timely reporting of the selenium loads associated with the flood flows and relatively quick agreement of the "incentive fee" to be levied on that proportion of the selenium loads judged to be the responsibility of the stakeholder agricultural drainers contributed to the perception of project success.

\subsection{Develop a field-based experimental approach to resolve scientific issues as they arise and} allow compliance monitoring program to be adaptive and responsive to new information There are few water resource management projects that begin with sufficient data to resolve scientific issues pertaining to environmental decisions that arise during project implementation. Once projects are underway, especially those that have taken time to negotiate, the prospect of making adaptive changes to the agreed-upon environmental compliance monitoring procedures can be daunting. However there is often a clear need for discrete data collection efforts directed at enhancing the basic science upon which decisions are based. During the first two years of the GBP a working subcommittee was formed, that reported to the TAC, with the mission of resolving outstanding selenium fate and transport issues and mobilizing research staff among the participating agencies to design, collect and analyze pertinent field data. Good inter-personal chemistry within this subcommittee and a genuine enthusiasm for field experimentation helped provide important data that resolved several important issues such as : (a) initial start-up protocol to minimize potential selenium release from Drain sediments; (b) distance downstream from major confluences of drainage channels to ensure adequate mixing and representative water quality sampling; before these issues became polarizing and adversely affected decision making within the TAC. The working committee group developed its own web page on an agency website, with an active link to the SFEI website and kept these web pages updated. The responsiveness to technical and scientific issues as they arose, and the efficient dissemination of new information as it was gathered and processed, helped to instill confidence and allay rumor within the stakeholder community and among those outside agencies and interest groups less directly involved in the project.

\subsection{Retain flexibility to allow landowners to innovate and adapt their operations to meet load targets.}

The TMDL approach to pollutant control often walks a fine line between encouraging stakeholder innovation and initiative on one hand and being over-prescriptive on the other. 
EDSS's need to develop simple models of complex systems in order to develop appropriate pollutant loading targets for watersheds - these models are sometimes used to partition pollutant loads among contributors based on factors such as historic loading or other economic-based policies (Wichelns, 1992). In some instances, providing gross basin-scale pollutant loading targets without partitioning loads at the sub-watershed or water district level can be beneficial by challenging local water districts and growers to come up with their own systems and formulas for partitioning basin pollutant loads equitably among their constituency. This deference to local autonomy helps to retain operational flexibility by supporting informal networking and provides greater opportunity for innovation. By developing a solution that relies on reasonable and attainable quantitative pollutant load targets while allowing local entities the freedom to develop their own pollutant control and policing protocols helped to ensure a successful outcome for the GBP.

To meet selenium load targets and avoid financial penalties water district stakeholders implemented an aggressive source control and drainage management program coupled with a subarea-wide drainage flow and water quality monitoring program. During the first year of the GBP continuous flow meters were installed at each of the main discharge points. The compliance monitoring program was developed to measure drainage discharge and selenium load for each district. Telemetered water quality sensors were installed allowing real-time access to each district's contribution to overall drainage flow (Figure 3). The web page shown in Figure 3 provides daily updates of measured flow, electrical conductivity and salt load based on 15 minute data - salt load is used by the water districts as a rough surrogate for selenium load, though in reality subsurface drainage flow and selenium load are not well correlated given the high spatial variability of groundwater selenium concentration in the project area. Water meters were retrofitted on drainage sumps and discharge points within each district in order to estimate the drainage flow contribution from each sump and the mass contribution to each District's selenium load. With this knowledge individual water districts were able to develop their own internal load targets based on correlations between selenium loads and monthly flows at individual tile drainage sumps.

Water districts also mandated drainage management policies throughout the subarea such as prohibition of tail-water return flows in the district-owned collector drains. These water districts worked with individual farmers to design and construct tail-water return systems so as to blend agricultural field drainage with surface water deliveries. Some deep tile drains were also retrofitted with in-line control weirs to allow selenium drainage discharges to be regulated. In the case of tile systems that discharged to sumps, sump pump control sensors were raised to allow discharge only when water tables in the field rose to within 5 feet of the ground surface. Similarly, shallow groundwater levels were assessed through the construction of field water level indicators, color coded floating risers that protruded from shallow monitoring wells observable from the roadside that revealed the red colored band of the riser when water levels were 
sufficiently high to affect crop yields from rise of salts into crop root zone. This clever device, publicly visible, provided indirect peer pressure to those landowners whose water management practices allowed excessive deep percolation after irrigation and was very effective at improving on-farm drainage source-control practices.

In the case of drains that discharged directly to open ditches - some main lines were severed and weir control structures installed at the outlet to help store more drainage water beneath each field prior to discharge to the District's drainage system. As a result of the project, more districts adopted tiered water pricing (Wichelns, 1992) or modified policies to further encourage drainage reduction. In particular, water district policies of implementing separate tiered pricing for preirrigation addressed the propensity for lower on-farm irrigation efficiencies at the beginning of the irrigation season. Districts have also installed regional recirculation systems, where subsurface drain water was collected and pumped back into the regional irrigation system.

\subsection{Effective implementation of environmental policy demands real-time integration of monitoring and water district operations.}

Until relatively recently TMDL's and other policies for pollutant management were practiced independently of water delivery decisions - being viewed as a regulatory paper-generating obligation rather than a set of procedures that needed to be integrated into water delivery operations. In larger water districts it is typical for separate departments to deal with water supply management and return flow water quality regulatory functions. In the GBP a commitment was made early to invest in state-of-the art monitoring technology and to utilize current telemetry technologies to serve the data to the stakeholder community. An example of early implementation of a real-time water quality monitoring and data dissemination system critical to water district operations is shown in Figure 3. The figure shows continuously monitored flow, electrical conductivity and temperature data and computed salt load near the terminus of the San Luis Drain - the regulatory compliance point for the GBP. Regression models developed between salt and selenium loading allowed the entity responsible for meeting monthly and annual selenium load targets to initiate drainage recirculation and temporary drainage storage operations to prevent exceedence of regulatory limits. During the first two years of the GBP innovative selenium load management techniques evolved and some existing drainage management practices were improved. One water district manager quipped that the water district had learned more about drainage management during the first two years of the GBP than they had in the past twenty.

The success with which the Grasslands Basin agricultural water districts have reduced drainage selenium discharges was shown in Figure 1. This graph compares selenium loads for the first eight years of the project (1997- 2003) with previous water years (1986 - 1996). Although selenium drainage targets were exceeded in January, February and April in the first year of the project this was not unexpected owing to the flooding that occurred due to El Nino conditions 
owing to higher than usual precipitation. The selenium load targets were based on mean monthly selenium loads recorded over a nine year period from 1985 - 1994, which included a sequence of drought years in the San Joaquin Basin and which contained no major flood events. Despite the challenges of the 1997 and 1998 El Nino years - average reductions of 60\% (compared to the pre-project mean monthly selenium loads) were achieved over a nine year period - making this project one of the most successful non-point source management initiatives ever undertaken by the US Bureau of Reclamation and its state and federal partners (Quinn et al, 1998, Environmental Defense Fund, 1994).

\section{Discussion and conclusions}

Although non-point environmental pollution policy and management in the United States relies more on regulation than in other western countries, it also tends to be more stakeholder-driven given a core belief in public involvement and accountability by the populace and an innate aversion to government regulation. Stakeholder involvement, accomplished successfully, relies heavily on coordination and communication. Where these are lacking, or not well thought-out long delays between project conception and implementation often result. Information technology and environmental decision support systems can play a significant role in meeting this need if timely, well designed and adaptive. There is unfortunately more evidence of failure than success in the area of environmental decision support. An Economist article (November 25, 2004) compiled statistics that revealed that $30 \%$ of all software projects are cancelled, $50 \%$ come in over budget, and $60 \%$ are considered failures by the organisations that initiated them (Mysiak, 2005). Learning to trust information technology and decision support systems takes time and requires the reinforcement of positive experiences.

Mysiak (2005) provided a useful framework for understanding the process of change with respect to adoption of new technologies. These can be divided into four steps - (a) an initial period of deconstruction where old techniques are unfrozen; (b) a second period of adaption to the new techniques; and (c) a final step of solidifying or refreezing as the new technology becomes habitual and is incorporated into standard practice. The example of the GBP fits well into such a model. The deconstruction process was long-drawn-out, suggesting that the courage to engage in the deconstruction process pre-supposes a valid alternative behavior. Once the project "Use Agreement" had been signed and put into practice the period of adaption began and the impacted agricultural water districts demonstrated remarkable innovation as they learned more about the relationships between water management and selenium drainage with the benefit of a simple environmental decision support system. One of the important lessons drawn from the GBP is that those environmental monitoring and decision support systems, that aid water and drainage management operations of the entity subject to compliance monitoring, should go handin-hand and be considered at the onset of the project. Monitoring programs should be developed systematically in a bottom-up, directed fashion and in a manner that documents progress toward 
a final monitoring plan document. It is paramount to promote irrigation and drainage management flexibility at the local level, providing an adaptive regulatory framework that encourages grower and water district innovation once the project is underway. It is important to communicate successes, recognize failures early when they occur, and be attentive to the advantages that new information technology can provide to disseminate project-relevant information and provide essential environmental compliance assurances to the public.

\section{Acknowledgements}

This work was supported by the US Bureau of Reclamation Science and Technology Program and the U.S. Department of Energy and LBNL under Contract No. DE-AC02-05CH11231. The author was part of the US Bureau of Reclamation's study team that initiated planning studies for the Grasslands Bypass Project in 1990 and later, as a member of the Technical Advisory Committee (TAC), developed a final monitoring plan and implemented the project on September 27,1996 . The author provided continuous monitoring data at several of the compliance monitoring stations for the first five years of the project. The success of the project has been due in large part to the dedication of the Technical Advisory Committee, who represent local landowners and water districts, four federal and two state agencies, a joint-powers water authority, several local government entities and private environmental organizations and interest groups. Mike Delamore, USBR, provided early leadership of the Project. The concept for the GBP was originally conceived in the early 1980's and known as the Zahm-Sansoni Plan.

\section{References}

Brickman R.J., S. Jasanoff and T.L. Ilgen. 1985. Controlling Chemicals: The Politics of Regulation in Europe and the United States Cornell University Press.

Environmental Defense Fund. 1994. Plowing New Ground. Using Economic Incentives to Control Water Pollution from Agriculture. Authors : T.F. Young, C.H. Congdon. Oakland, CA.

Jasanoff, S. 2005. Designs on Nature: Science and Democracy in Europe and the United States. Princeton University Press.

Karkoski J. 1994. A Total Maximum Monthly Load Model for the San Joaquin River. Regional Water Quality Control Board.

Mysiak J. 2005. Slide presentation during ISESS Conference, 2005. Seisembra, Portugal. May 5-8, 2005.

Narasimhan T.N. and N.W.T. Quinn. 1995. A process - oriented view of issues of salinity and drainage in the western San Joaquin Valley of California. LBNL-38498, Earth Sciences Division, Berkeley, California. 
Quinn N.W.T. 1996. Compliance monitoring program for use and operation of the Grasslands Bypass to remove agricultural drainage from Grassland Water District channels. LBNL39052. Earth Sciences Division, Berkeley, California.

Quinn N.W.T. and J. Karkoski. 1998. Potential for real time management of water quality in the San Joaquin Basin, California. Journal of the American Water Resources Association, Vol. 36, No. 6, December.

Quinn, N.W.T., J. McGahan and M. Delamore. 1998. Innovative drainage management techniques to meet monthly and annual selenium load targets. California Agriculture, Vol. 52, No. 5, September-October. 1998.

Quinn N.W.T and W. M. Hanna. 2003. A Decision Support System for Adaptive Real-Time Management of Seasonal Wetlands in California. 2003. Environmental Modelling and Software. Vol. 18, Issue 6, pp 503-511. Elsevier Science Ltd.

Quinn, N.W.T, J.C. Linneman and K.K. Tanji. 2006. The San Joaquin Valley Westside Perspective. World Environmental and Water Resources Congress 2006. ASCE EWRI. LBNL-60613. May 22, 2006.

San Francisco Estuary Institute. 1997 - 2006. Grassland Bypass Project Annual Reports, Richmond, CA.

Swain, D.G. and N.W.T. Quinn. 1991. Supplemental Environmental Assessment and Draft Finding of No Significant Impact, Proposed Use Agreement Allowing Use of the San Luis Drain. Appendix I: Analysis of the Potential Water Quality Impacts Resulting from the Proposed use of the San Luis Drain by Grasslands Drainers. USBR Mid Pacific Region, Sacramento, CA.

US Bureau of Reclamation. 1995. Finding of No Significant Impact and Supplemental Environmental Assessment. Grassland Bypass Channel Project. Interim Use of a Portion of the San Luis Drain for Conveyance of Drainage Water through Grassland Water District and Adjacent Grassland Areas. Nov. 1995. USBR, Mid-Pacific Region, Sacramento, CA.

Wichelns D. 1992. Regional Economic Incentive Programs to Reduce Drainage Water Volume and Improve Water Quality. University of Rhode Island, Kingston, RI.

Wichelns D. and D. Nelson. 1989. An Empirical Model of the Relationahip between Irrigation and the Volume of Water Collected in Subsurface Drains. Agricultural Water Management, Vol. 16, pp. 293-308.

Wichlens D. and M. Weinberg. 1990. Economics of Agricultural Drainage Policies. California Agriculture, Vol. 44, No. 4, Jul/Aug 1990, pp. 8-10. 


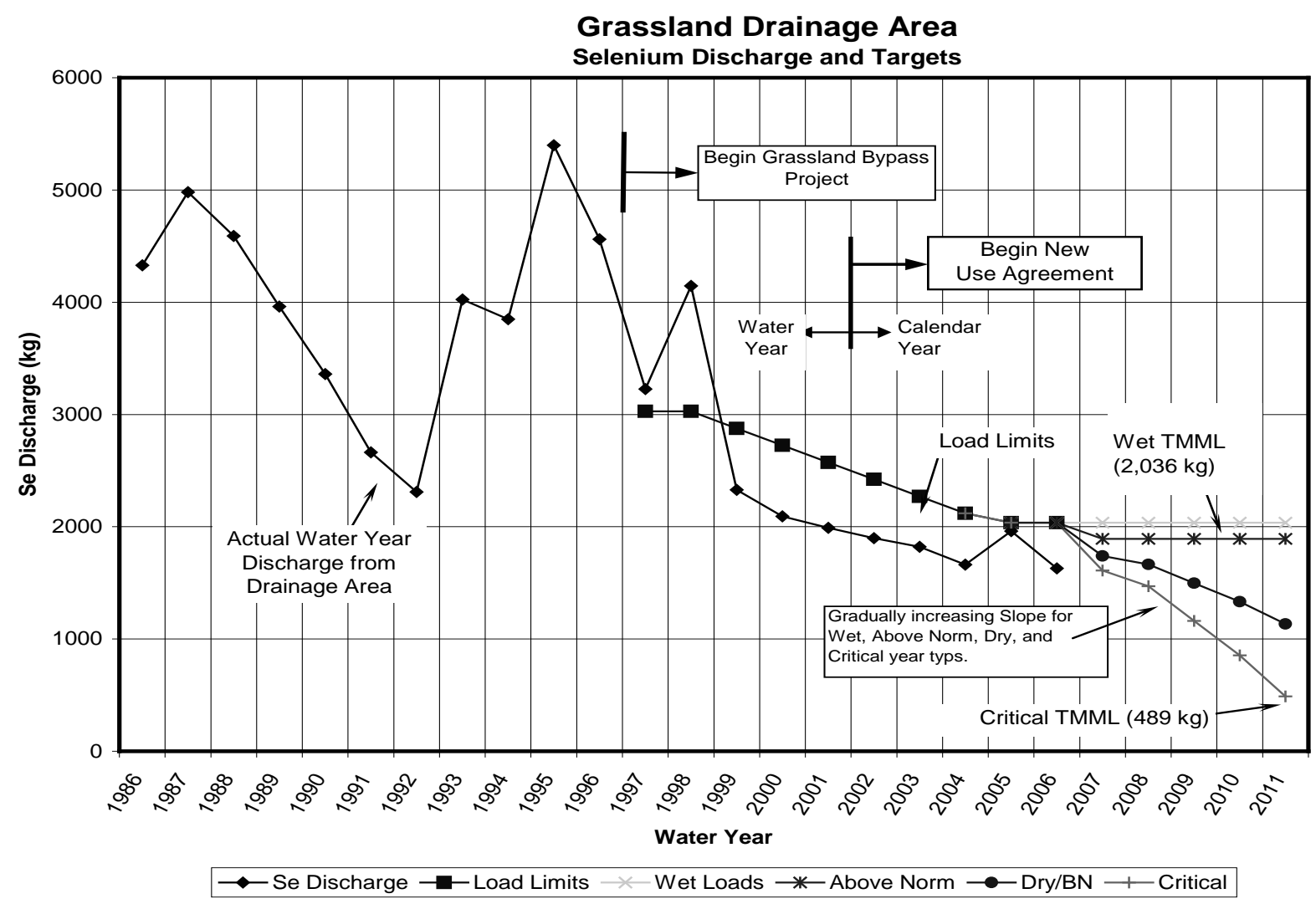

Figure 1. Comparison of pre-project and post-project selenium loading showing the success of the Grasslands Bypass Project (GBP) in controlling selenium drainage export from irrigated agriculture on the west-side of the San Joaquin Basin. 


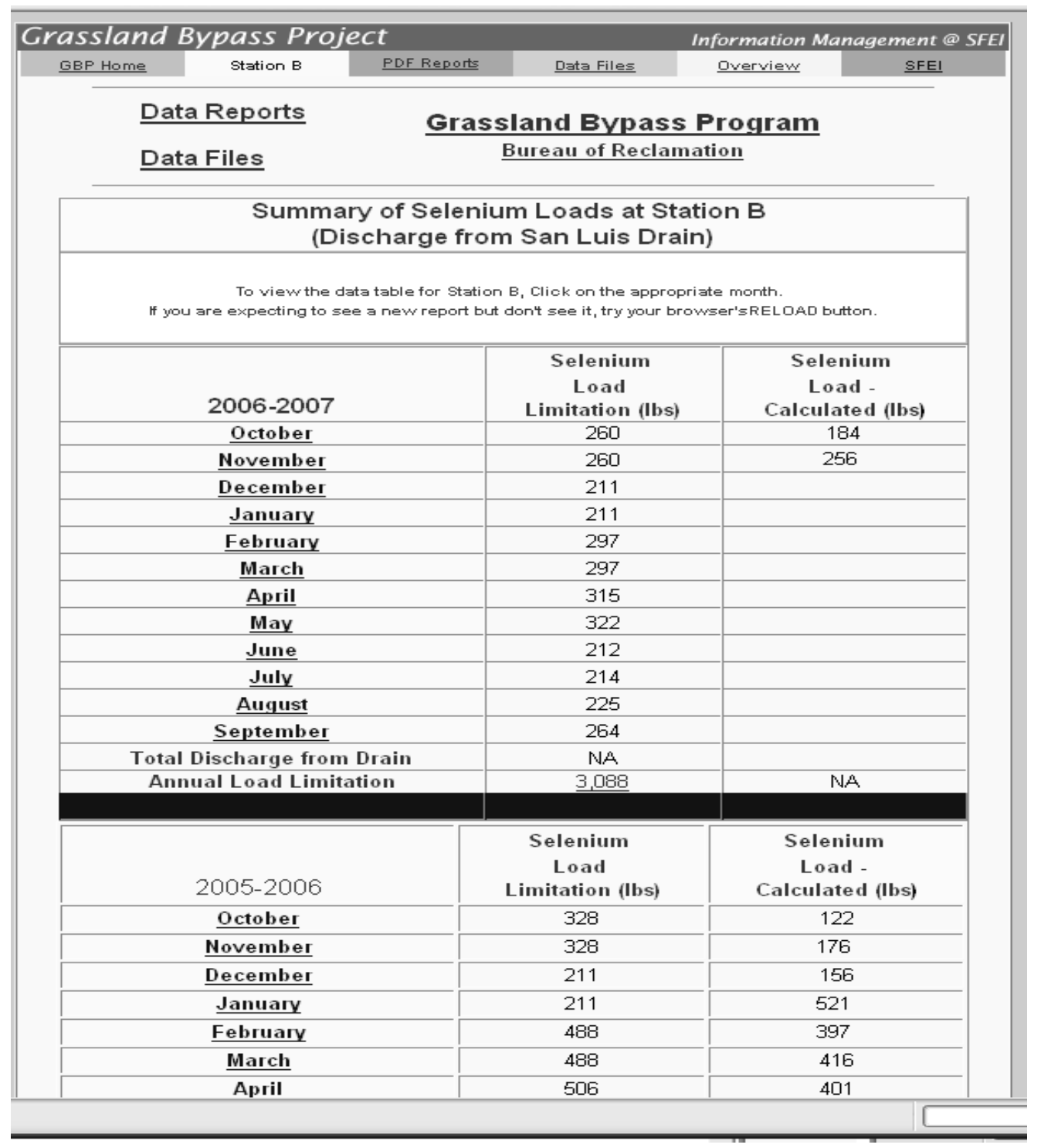

Figure 2. Data reporting system developed by the Grassland Bypass Project (GBP) and maintained by the San Francisco Estuary Institute (SFEI). The selection of a neutral, independent environmental organization lent credibility to the project and provided assurances of unbiased reporting to stakeholders and the public. 


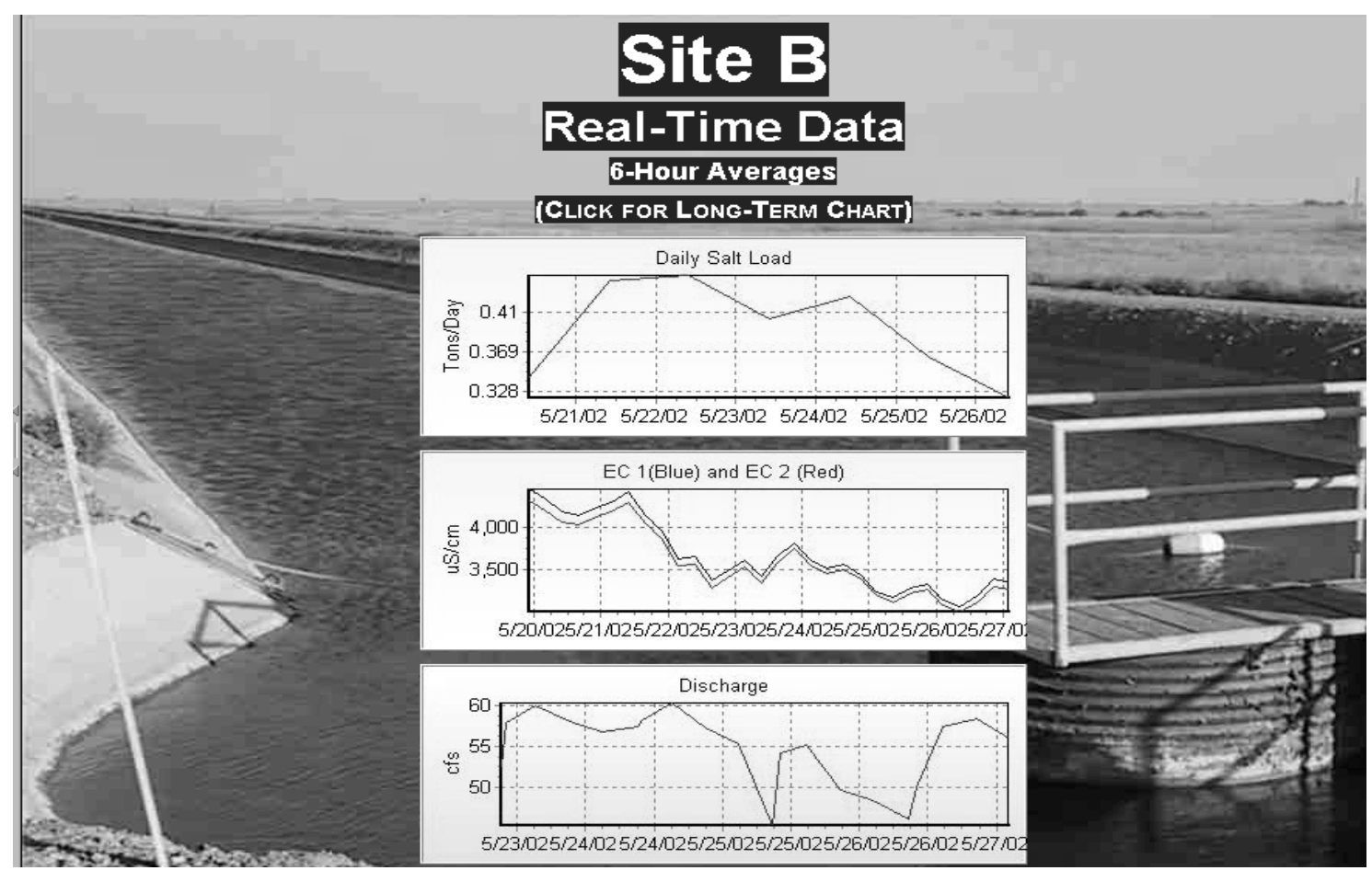

Figure 3. Reporting of real-time flow, electrical conductivity and salt loading at the project compliance monitoring station near the San Luis Drain terminus. 